\title{
ANTONIO TABUCCHII E A CONSTANTE INCONSTÂNCIA DO AMOR NA PÓS-MODERNIDADE
}

\author{
ANTONIO TABUCCHI AND THE INCONSISTENCY \\ OF LOVE IN POST-MODERNITY
}

\author{
Karla Renata Mendes \\ Universidade Federal de Alagoas, Arapiraca, Alagoas, Brasil \\ karla.mendes@arapiraca.ufal.br
}

Resumo: Antonio Tabucchi, escritor italiano falecido em 2012, ganhou notoriedade pela tradução, pesquisa e difusão da obra de Fernando Pessoa. Como ficcionista, alcançou êxito a partir da década de 80 com a publicação de livros como $O$ jogo do reverso (1981) e Afirma Pereira (1994). Desde então, destacou-se no cenário dos grandes nomes da literatura contemporânea com uma extensa e variada produção literária traduzida para diversas línguas e com adaptações para o cinema. Seus textos, permeados de características do pós-modernismo, apresentam-se ao leitor como um retrato da observação da realidade e dos sujeitos em constante transformação e instabilidade. Exemplo disso é o texto aqui destacado, "Bom como você é", que compõe a obra Está ficando tarde demais, publicada em 2001. Desenvolvido em forma de epístola, a carta problematiza uma das facetas mais presentes e mais passíveis de mudanças na vida humana: o sentimento amoroso. Assim, o artigo tem por objetivo refletir sobre a obra de Tabucchi, investigando seus diálogos com a pós-modernidade e a forma com que aborda questões tipicamente contemporâneas como a fragilidade das relações, a inconstância que cerca o indivíduo e a fluidez das identidades.

Palavras-chave: Antonio Tabucchi; Está ficando tarde demais; Pós-modernidade; Amor; Identidade

Abstract: Antonio Tabucchi, an Italian writer deceased in 2012, gained notoriety for his translation, research and promotion of Fernando Pessoa's works. As a fiction writer, he was successful since the 1980s with the publication of books such as O Jogo do Reverso (1981) and Afirma Pereira (1994). Since then, he stood out among the great names of contemporary literature by his large and varied body of work which became widely translated and received many movie adaptations. His texts, full of postmodernist features, present themselves to the readers as a portrait drawn from observation of reality and ever-changing unstable individuals. One example is the text highlighted here, "Bom como você e", which integrates the 2001 work Está ficando tarde demais. Written as an epistle, the letter investigates one of the most prominent and shifting dimensions of human life: the feeling of love. Therefore, the present article aims to reflect on Tabucchi's work, looking into its dialogues with post-modernity and the way it faces typically contemporary questions such as the frailty of relationships, the inconsistency that surrounds the individual and the fluidity of identities.

Keywords: Antonio Tabucchi Está ficando tarde demais; Post-modernity; Love; Identity

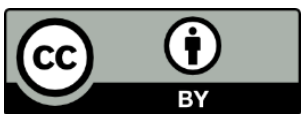


O "maior autor de língua italiana contemporânea". É assim que Ignácio de Loyola Brandão se referiu ao amigo e tradutor de Zero, Antonio Tabucchi, em artigo publicado no jornal $O$ Estado de São Paulo, em 2012, na ocasião da morte deste. A assertiva do brasileiro dava indícios da relevância do escritor italiano no cenário literário. Além da pesquisa e tradução da obra de Fernando Pessoa, fatores que por si só fizeram com que seu nome se destacasse nas letras, Tabucchi, que iniciou a publicação de seus livros em meados da década de 70, foi ganhando cada vez mais notoriedade também como escritor de romances e contos. Com o surgimento de Afirma Pereira (1994), uma de suas obras mais famosas e que seria adaptada para o cinema no ano seguinte, ele obteria a ascensão definitiva no rol de grandes nomes da literatura de nossa época. A heterogeneidade de suas criações, o caráter metaliterário, a intertextualidade e fragmentação de seus textos e o enfoque em temas como a identidade, a experiência complexa de vivenciar o tempo ou a memória contribuíram para que sua escrita fosse vista como um reflexo da pós-modernidade.

Nesse sentido, observa-se que a análise de diferentes textos a respeito do PósModernismo indica que as tentativas de teorização do assunto passam, necessariamente, pela dificuldade de encerrar em limites precisos e absolutos um tema tão "escorregadio". Linda Hutcheon, por exemplo, já inicia seu texto Poética do Pós-Modernismo, deixando clara sua opinião de que o fenômeno sobre o qual se debruça é fundamentalmente "contraditório" e que "usa, abusa, instala e subverte os próprios conceitos que desafia" (HUTCHEON, 1991, p. 19). Para David Harvey, se a Modernidade já assinalava uma ideia de fragmentação, efemeridade e transformação caótica, tais perspectivas são exacerbadas na pós-modernidade em um processo muito mais complexo e mutável, e assim o pós-modernismo é aquele que "nada, e até se espoja, nas fragmentárias e caóticas correntes da mudança, como se isso fosse tudo o que existisse." (HARVEY, 1992, p. 49). Já em Zygmunt Bauman, acentua-se a ideia de que o fenômeno da pós-modernidade nos confronta, justamente, com a ausência de regras definitivamente estabelecidas, uma vez que "as regras estão perpetuamente se fazendo, sendo buscadas e encontradas, cada vez de uma forma analogamente única e como um evento analogamente único, em cada sucessivo encontro com os olhos, os ouvidos e a mente do leitor, espectador, ouvinte.” (BAUMAN, 2004, p. 133). Em O fim da modernidade, por sua vez, o filósofo italiano Gianni Vattimo afirma haver uma "dificuldade real" de "identificar um autêntico caráter de mudança radical nas condições - de existência, de pensamento - que se indicam como pósmodernas, em relação às características gerais da modernidade, o que tornaria "qualquer discurso sobre a pós-modernidade contraditório". (VATTIMO, 2002, p. viii-ix). Por fim, no Brasil, Leyla Perrone Moisés, ao comparar a modernidade e a pós-modernidade, afirma que essa última é

muito mais difícil de ser definida por conceitos ou examinada a partir de práticas particulares (visíveis, como traços estilísticos, na arquitetura, muito menos visíveis na literatura), o que se deve tanto a sua heterogeneidade e indeterminação de princípio quanto a sua condição de algo que está sendo feito "agora mesmo", algo que ainda não nos oferece, e nem pretende oferecer, nenhuma perspectiva futura. (PERRONEMOISÉS, 1998, p. 188-189).

Se o caminho é espinhoso e o número de problemas levantados nem sempre encontra um número correspondente de respostas, é inegável que a pós-modernidade trouxe consigo mudanças que, apesar de instáveis e de limites imprecisos, provocam um novo olhar sobre o mundo, os sujeitos e a realidade. Compactuando com a ideia defendida por Frederic Jameson de que o pós-modernismo "não é apenas mais um termo para a descrição de determinado estilo", 
mas é também, "um conceito de periodização cuja principal função é correlacionar a emergência de novos traços formais na vida cultural com a emergência de um novo tipo de vida social e de uma nova ordem econômica" (JAMESON, 1985, p. 17), entende-se aqui que os textos de Antonio Tabucchi refletem, justamente, esse "novo tipo de vida social", escancarando ao leitor as contradições que emanam da vida contemporânea, que cindem o sujeito e tensionam também a própria criação artística. Por isso, o mais comum é nos depararmos, ao longo dos livros do escritor italiano, com personagens que transitam em meio a um mundo plural, em constante movimentos internos e externos, procurando caminhos que não são estáveis, descobrindo a si mesmos enquanto questionam (e encontram ou não) seus diferentes "eus". Na transposição ficcional desse mundo e dos indivíduos em permanente mutação e fragmentação, o autor não se rende a uma visão unívoca e centralizadora do real, mas o aborda a partir de diferentes perspectivas, afinal, como afirma Terry Eagleton, a pós-modernidade coloca em revisão as "noções clássicas de verdade, razão, identidade e objetividade, a ideia de progresso ou emancipação universal, os sistemas únicos, as grandes narrativas ou os fundamentos definitivos de explicação." (EAGLETON, 1998, p. 7).

Assim, pode-se dizer que surge, a cada parágrafo, como afirma o próprio Tabucchi, no prefácio à edição italiana da obra Jogo do reverso, a "imprevisível circunstância da vida de que uma certa coisa que era assim, também era de outra maneira." (TABUCCHI, 1998, p. 5). ${ }^{1}$ Essa ambiguidade que permeia sujeitos e situações, que não permite um encontro com a Verdade, mas com a multiplicidade de verdades possíveis, relaciona-se diretamente ao fato de o pósmodernismo, como afirma David Harvey, propor um "contra-ataque a presunções universalizantes" (HARVEY, 1992, p. 52) e um questionamento permanente da noção de unidade à qual o indivíduo poderia estar subordinado.

Nesse contexto, situa-se a obra Está ficando tarde demais, publicada em 2001 e formada por espécies de "contos epistolares". A falta de limites precisos entre o conto e carta advém da própria dificuldade de classificação dos textos que compõem o livro. Segundo Harvey, nota-se no pós-modernismo um "perpétuo entretecer de textos e sentidos" (HARVEY, 1992, p. 54) e o impulso dominante é o de "procurar, dentro de um texto por outro, dissolver um texto em outro ou embutir um texto em outro" (HARVEY, 1992, p. 54). Assim, o subtítulo - "Romance em forma de cartas" - mais do que enquadrá-lo em um possível gênero, evidencia o jogo ambíguo que perpassa toda a obra. Conforme quer sugerir o autor, trata-se de um romance, mas em que medida pode-se entender isso que se chama aqui de romance? O gênero se desenvolve ao longo das cartas? As cartas contêm uma matéria romântica? Como se perceberá ao longo da leitura, não há linearidade, personagens, espaço, tempo e enredo fixos, estabelecendo-se ali, em grande medida aquilo que, segundo Hutcheon, seria característico do pós-modernismo: uma "relação intertextual paródica com as tradições e as convenções dos gêneros envolvidos." (HUTCHEON, 1991, p. 28). Assim, cada carta apresenta um novo universo com novos sujeitos e novas situações totalmente independentes, atadas, a princípio por um único fio comum: a temática amorosa. As dezoito cartas que compõem a obra também subvertem a estrutura tradicional do gênero epistolar, seguindo um padrão de composição que apresenta apenas título, destinatário da missiva e texto, excluindo, assim, outros elementos comuns ao gênero, tais como local, data, despedida. Os remetentes são sempre masculinos e os destinatários mulheres, com exceção da última carta. Os vocativos ("minha querida", "querida

\footnotetext{
${ }^{1}$ No original: "Le imprevedibili circostanze della vita, che una certa cosa, che era 'così' era invece anche in un altro modo".
} 
queridíssima querida", “amor”, “amiga") dão indícios da relação íntima que aproxima os personagens.

É nesse sentido que Tabucchi, no post-scriptum à obra, oferece uma tentativa de definição da essência desses textos:

\begin{abstract}
Se me pedissem para me pronunciar sobre a natureza destas cartas feitas romances não excluiria defini-las como cartas de amor. Em um sentido bastante lato, assim como é vasto o território do amor, que invade muitas vezes territórios ignotos e aparentemente não seus, como o rancor, o ressentimento, a nostalgia, o remorso. Que são alguns dos lugares por onde estes personagens, remetentes das epístolas que pus a escrever, vagam como perdidos. (TABUCCHI, 2004, p. 190)
\end{abstract}

Como afirma o escritor, ao longo das cartas são retratadas situações e personagens que exploram as mais variadas contradições do amor: a saudade, a distância, a traição, o reencontro ou desencontro, o abandono, o arrependimento, a espera, a decepção, o desejo, o sexo. Através de narrativas e diálogos entrecortados, histórias de amor vão tomando corpo à medida que os personagens deixam os pensamentos, sentimentos e emoções fluírem sem a exigência de uma ordem e sequência lógicas. Tal fragmentação parece decorrer também da essência do gênero epistolar, afinal a carta é um testemunho íntimo, pessoal em que apenas remetente e destinatário conhecem os pormenores das situações que engendraram e antecederam a escrita do texto. Aos leitores, como elemento "intruso" nessa equação, cabe a tarefa de tentar preencher as lacunas das histórias que acompanham, uma vez que é peculiar da arte pós-moderna estimular os receptores do texto ou imagem "a produzir uma significação que não poderia ser unívoca nem estável." (DERRIDA apud HARVEY, 1992, p. 55). A estabilidade do texto e da recepção é contestada aqui, também, pela fluidez que emana do estilo das cartas. Diferentes sujeitos, inseridos em acontecimentos diversos, requerem diversas formas de narrar. Assim, Tabucchi reinventa-se a cada carta, havendo variações na linguagem: um tom mais amargo e irônico em certas ocasiões, delicadeza e singeleza em outros momentos, um vocabulário mais agressivo ou de forte conotação sexual vão se alternando conforme o remetente e o tema da epístola. Confirma-se, assim, a hipótese de que no pós-modernismo é "vão tentar dominar um texto, porque o perpétuo entretecer de textos e sentido está fora do nosso controle; a linguagem opera através de nós" (HARVEY, 1992, p. 54) e, assim, múltipla, ajusta-se à necessidade de cada personagem e de cada narrativa.

O que, paradoxalmente, parece uma constante ao longo de toda a obra, é justamente a certeza da inconstância que assola as relações humanas e os indivíduos. A epígrafe do livro, uma canção popular italiana (Avanti, 'ndrè / avanti, 'ndrè / Che bel divertimento. / Avanti, 'ndrè / avanti, 'ndrè / la vita è tutta qua. $)^{2}$, já deixa clara a ideia de que todos estão submetidos a constantes reviravoltas e que os sujeitos, os relacionamentos e a própria vida estão em permanente transformação. Se na pós-modernidade tudo se mostra muito mais fluido, em constante movimento como os passos de uma dança, as relações interpessoais certamente se ressentem deste fator. É o que Zygmunt Bauman afirma no livro Amor líquido, destacando a fragilidade das conexões estabelecidas na "nossa líquida sociedade moderna":

Desligados, precisam conectar-se... Nenhuma das conexões que venham a preencher a lacuna deixada pelos vínculos ausentes ou obsoletos tem, contudo, a garantia da permanência. De qualquer modo, eles só precisam ser frouxamente atados, para que

\footnotetext{
${ }^{2}$ Para frente, para trás / para frente, para trás / que divertido. / Para frente, para trás / para frente, para trás / isso é que é a nossa vida.
} 
possam ser outra vez desfeitos, sem grandes delongas, quando os cenários mudarem - o que, na modernidade líquida, decerto ocorrerá repetidas vezes. (BAUMAN, 2004, p. 7)

A instabilidade dos vínculos afetivos e a facilidade do esfacelamento das uniões que, em nossa época, ocorrem por motivos cada vez mais banais e com uma rapidez assustadora é também enfocada no conto-carta "Bom como você é". Percebe-se que esse texto, em especial, enquadra-se em um tipo peculiar de carta mencionada pelo próprio Tabucchi em seu postscriptum:

O que mais me inquieta e rói, como um cupim teimoso metido numa velha mesa e que é impossível fazer com que se cale a não ser com um veneno que nos envenenaria também, é a carta que nunca escrevemos. "Aquela" carta. Aquela que todos nós sempre pensamos em escrever, em certas noites insones, e que sempre deixamos para o dia seguinte. (TABUCCHI, 2004, p. 190)

A carta aqui analisada contém justamente a faceta de ser "aquela" carta. Escrita sob o domínio das mais fortes emoções, de sentimentos como a vingança e o rancor, que escapam a qualquer racionalidade. Como se percebe ao longo da leitura do texto, a carta nada mais é do que a resposta a uma missiva recebida sete anos antes. Como em outras cartas, aqui também há a imersão de uma narrativa dentro da narrativa, pois, embora o leitor se depare com um texto dedicado a um destinatário feminino - "Minha querida" -, seu início denota as palavras também em uma voz feminina: ““...porque assim não pode continuar [...] eu tenho o dever de pensar em mim mesma, portanto, de me proteger. Houve noites em que pensei: Mas eu, o que sou para ele?"' (TABUCCHI, 2004, p. 105). A abertura de aspas e as reticências indicam um discurso entrecortado, reproduzido. O que se entende na continuação é que, no princípio, não se trata das palavras do emissor, mas que este apenas está citando o discurso da carta que recebera anteriormente.

Nem destinatário nem remetente são nomeados, e as circunstâncias descritas nos levam a saber pouco sobre eles. Trata-se de um casal que se separa em condições adversas, uma vez que ele, médico de uma Organização Mundial de Saúde, e, portanto, em constante deslocamento graças ao seu trabalho humanitário, ao voltar de uma de suas viagens, descobre ter sido abandonado e, no lugar da esposa, teria encontrado apenas uma carta. Seriam trechos exatamente dessa carta de despedida os reproduzidos por ele no início da sua própria redação como uma espécie de introito aos motivos que o levaram a escrever depois de passados tantos anos. O que se sabe é que as linhas deixadas pela mulher tentavam explicar o abandono dando como principal justificativa o fato de ela já não suportar mais viver sozinha, e, ao mesmo tempo, comunicava ao marido que encontrara conforto ao lado de outro homem (Gianni, ou como ironicamente se refere o emissor "Giannischicchio", referindo-se ao personagem do "Inferno", na Divina Comédia), restando-lhe apenas partir. Assim, o mote central da narrativa constrói-se em torno de uma das afirmações da mulher em relação ao companheiro: "e tenho certeza que, bom como você é, conseguirá compreender tudo o que..." (TABUCCHI, 2004, p. 106). Nesse momento, a reprodução das palavras da mulher é cortada, e, apesar de seu discurso permanecer como "eco" às palavras do emissor, é ele quem assumirá a sequência da carta. A partir daqui, seu ponto de vista e seus sentimentos virão a lume e se entenderá o porquê da missiva.

Se, como afirma Bauman, a identidade é comparada a um "quebra-cabeças incompleto, ao qual faltam muitas peças" (BAUMAN, 2005, p. 54), o conto problematiza essa questão, salientando o quanto a formação identitária é complexa para o sujeito, pois, além da tentativa 
individual de definição de quem se é, o indivíduo também lida com a interpretação e as expectativas dos outros a seu respeito. Vemos que, para mulher, a identidade construída para o marido como "bom" (desenvolvia um trabalho voluntário e humanitário, sacrificava-se e doavase em prol de terceiros), ainda que ausente, levou-a a acreditar que ele também compreenderia sem maiores dificuldades o abandono e a traição. Essa perspectiva dos fatos apenas acentua, como destaca Bauman, o quanto "temos opiniões definidas sobre como fazer as coisas e sobre como os outros deveriam ser" (BAUMAN, 2004, p. 32), sendo justamente a fragilidade dessas certezas a temática problematizada na narrativa de Tabucchi. Isso porque apesar de, ao longo do conto, o homem repetir constantemente coisas como "entendi perfeitamente", "acha que não sou capaz de entender", "isso também é compreensível", "mereceu a minha mais sincera compreensão", "compreendi perfeitamente", vemos que a possível identidade de um sujeito "bom", generoso e absolutamente compreensivo em todos os âmbitos não se coaduna à realidade. Da mesma forma que ela construíra uma identidade para ele, pode-se imaginar que ele também esperasse nela a concretização de suas expectativas (fidelidade e companheirismo) quanto a um relacionamento amoroso. Por isso tornar-se-á óbvio seu rancor ao voltar e se deparar com a ausência da mulher.

Além do sentimento de traição e abandono, evidenciados pelo tom de mágoa e ironia que perpassam o conto, o emissor destaca a surpresa com aquilo que julga ser uma prova da volatilidade da relação:

\footnotetext{
Sabe, em toda a sua carta, que é tão sincera e que mereceu a minha mais sincera compreensão, tem uma coisa que não está certa. Talvez lhe pareça estranho, ou um detalhe insignificante, mas é quando você me diz que respondeu a um pedido de afeto. Ou melhor, que você respondeu a um pedido de amor. A um amor se corresponde quando se está apaixonado, minha querida, e isso eu esperava que você me tivesse escrito, com a grande lealdade que sempre caracterizou a nossa vida. Você poderia (ou melhor, deveria) ter me dito: Sabe aconteceu que, quando você não estava, eu me apaixonei. Pouco ou muito não tem importância, porque há várias graduações no amor, assim como na febre, pode ser um febrão ou uma febrícula, mas em todo caso é uma elevação de temperatura. Mas, não, você me apresenta o seu Giannischicchio assim, como se fosse um refresco. Como quem diz: Sabe, você não estava, e enquanto isso tomei um refresco. (TABUCCHI, 2004, p. 109-10)
}

Como aponta o emissor, através da mordaz sugestão do "refresco", nunca foi tão fácil substituir um parceiro ou romper um relacionamento como em nossa contemporaneidade. $\mathrm{Na}$ modernidade líquida, como afirma Bauman, as relações pessoais se desenvolvem cada vez mais a partir de um "modo consumista", o qual "requer que a satisfação precise ser, deva ser, seja de qualquer forma instantânea, enquanto o valor exclusivo, a única 'utilidade' dos objetos é a sua capacidade de proporcionar satisfação." (BAUMAN, 2005, p. 70). Assim, quando a satisfação se interrompe, quando o "objeto" se desgasta, torna-se familiar demais e pode ser trocado por uma versão nova e mais estimulante, não haveria razões para "entulhar a casa com objetos inúteis. [Por isso], no caso dos relacionamentos, você deseja que a 'permissão de entrar' venha acompanhada da 'permissão de sair' no momento em que não veja mais razão para ficar." (BAUMAN, 2005, p. 70-71).

Para Bauman, o que impera é a constatação de que muitas relações tornaram-se absolutamente descartáveis, flexíveis, flutuantes, preservadas em grande parte apenas pela utilidade e satisfação que oferecem. E tal perspectiva é enfocada na narrativa tabucchiana tanto na personagem feminina, como também na figura do próprio remetente e de Gianni. Quanto a esse último, sabe-se que está no terceiro relacionamento, tendo netos do primeiro casamento e 
filhos da segunda união, desfeita justamente em virtude do novo envolvimento, definido ironicamente na carta, como um "amor fou”. Já o narrador, uma vez sozinho, encontrou em uma nova companheira a comodidade adequada aos seus interesses:

Entretanto, encontrei a Giovanna. Que também me quer bem. E eu a ela. Ingênua, é
ingênua, não nego, mas é preciso levar em consideração a idade que ela tem, no fundo,
em relação a você é uma garota, (...) e quis um filho meu e conseguiu, coisa que nós
dois nunca conseguimos. (...) Não é uma mulher complicada (...) e juro que a sua
maior satisfação foi mudar o parquê. Mas pelo menos não fica nervosa, e seu eu viajo
por alguns meses não me faz choradeiras, não se sente uma pobre derrelita como
acontece com certas mulheres que não conseguem estar mais de uma semana sem um
homem. (TABUCCHI, 2004, p. 112) [grifos nossos]

Assim como Gianni se ajustara às necessidades da mulher, Giovanna (nota-se a semelhança inclusive no nome) simplesmente adequara-se à nova situação do remetente, e, embora tivesse pouco a oferecer, também não exigia muito, o que acaba por ser uma espécie de compensação para o possível vazio do relacionamento. O que se percebe também é que cada vez mais o tom da carta, ainda que irônico, vai permitindo entrever o rancor e a mágoa latentes. As comparações implícitas entre a antiga e a nova situação amorosa evidenciam o ar provocativo do emissor. Nota-se a tentativa de humilhar a mulher, ao mencionar, por exemplo, a condição da maternidade fracassada de outrora e realizada com êxito no presente. Dessa forma, a verdadeira razão da escrita da carta vai se delineando cada vez com mais precisão: trata-se de uma vingança, um revide ao sofrimento provocado anos antes e é esse o sentimento que se avulta e domina a narrativa nos parágrafos finais.

Como se sabe pelas palavras do narrador, a esposa teria partido com Gianni para Foz do Iguaçu porque esse recebera um convite para atuar como engenheiro em uma obra de grande porte. Passados sete anos, no momento atual da escrita, ele descobre que o casal retornara à Itália: "Por pura casualidade fiquei sabendo que você e Gianni tinham voltado. A barragem ficou pronta, e já era hora que vocês voltassem, disse-me por acaso o médico que trata o Gianni, que como você sabe é um bom amigo meu." (TABUCCHI, 2004, p. 112). Nesse ponto, o texto que, anteriormente, preocupara-se em resgatar os meandros do passado e da separação, ganha uma nova perspectiva temporal: trata-se do momento presente. Visitando o consultório do amigo e médico de Gianni e lá se encontrando sozinho, o narrador acaba tendo acesso aos exames do "Giannischicchio", e a descoberta de que ele estava gravemente doente, vítima de um "sarcoma na próstata", foi, na verdade, o que o incitara a escrever desde o princípio:

Pois então, bom como sou, pensei em eu mesma avisá-la, já que apesar de tudo continuo sendo seu amigo. Quando se entra em metástase completa, as dores são muito fortes, realmente muito fortes, e Gianni vai ganir como um cachorro. E você ficará aterrorizada, por que os gemidos de um doente assim são a pior coisa que se pode ouvir. E num país como o nosso, onde a terapia da dor não é absolutamente levada em consideração, o farão sofrer realmente como um animal, porque os médicos têm medo de enfrentar os rigores da lei se receitarem doses de morfina superiores às consentidas. (TABUCCHI, 2004, p. 113-14)

A vingança do emissor pela traição e abandono experimentados anteriormente se dá de uma maneira mais do que cruel ainda que pontuada por um irônico "bom como sou". Se ele fora simplesmente "trocado" por outro, agora tinha o prazer de informar que justamente esse outro era acometido por uma terrível doença e as perspectivas de evolução do quadro o encaminhavam para uma eminente morte. Ao discorrer sobre os efeitos da enfermidade, um 
verdadeiro sadismo toma conta do enunciador, há prazer em revelar o quanto haverá de sofrimento, de tristeza, de dor física e psicológica. Como se observa, a justificativa irônica para ser o portador de uma notícia tão nefasta e fazê-lo nesses termos, decorre justamente da antiga presunção da esposa a seu respeito. Correspondendo ao pressuposto de ser "bom", seu ato era quase um obséquio.

Contrariando possíveis vestígios de benevolência, que se esperavam intrínsecos à sua personalidade, o narrador continua seu discurso pontuado de cinismo e desdém, como se observa na sequência:

\footnotetext{
Caso isso [o padecimento de Gianni] se verifique, como acho que se verificará, você pode se dirigir a mim, tenho duas malas de morfina, com as quais viajo pelo mundo, não tenho nenhum problema em lhe abastecer do que for necessário. Em todo caso, me avise antes do final de dezembro, porque depois eu e a Giovanna planejamos fazer uma longa viagem pelo México e provavelmente só voltaremos depois da entrada da primavera, percorreremos todo o Yucátan e talvez a gente dê uma espichada até a Guatemala. (TABUCCHI, 2004, p. 114)
}

Ao encerrar a carta, o emissor reforça a finalidade vingativa de seu escrito. Assim, pode-se dizer que o texto possui uma estrutura quase cíclica, pois o personagem que inicia a narrativa abandonado, sofrendo, humilhado, enquanto a mulher, feliz, viajava acompanhada por outro para um lugar paradisíaco, aparece no fim em uma posição de superioridade, constatando e fazendo questão de evidenciar como a situação se invertera. Agora, quem deveria se sentir humilhada, sozinha, suportando grandes sofrimentos era ela, enquanto a ele eram concedidos os prazeres de uma longa viagem ao lado da jovem Giovanna.

Tabucchi afirma que "vasto é o território do amor". Tão vasto a ponto de, por vezes, ultrapassar suas fronteiras habituais e invadir os limites do ódio, rancor e ressentimento. Esse texto explora justamente as facetas contraditórias incitadas pela paixão. Por isso, para Bauman, o amor é "uma hipoteca baseada num futuro incerto e inescrutável, pode[ndo] ser, e frequentemente [sendo], tão atemorizante quanto a morte. Só que ele encobre essa verdade com a comoção do desejo e do excitamento." (BAUMAN, 2004, p. 23). Sem mascaramentos, a carta coloca essa "faceta atemorizante" do amor em evidência, uma vez que o lugar da enunciação é o da mágoa e da vingança, ele torna-se sinônimo da aniquilação, da destruição do bem, que, um dia, já foi amado. Dessa forma, Tabucchi relativiza as verdades tidas como absolutas e os pontos de vista consensuais sobre os sujeitos e situações, inclusive sobre o amor, algo amplamente explorado ao longo de todas as cartas que compõem o livro Está ficando tarde demais.

$\mathrm{Na}$ esteira da pós-modernidade, observa-se que a liberdade concedida ao artista e ao receptor, bem como a nova concepção do status do objeto artístico, conduzem a uma aproximação visceral entre arte e vida. Bauman, por exemplo, vê tal questão sob uma perspectiva positiva, uma vez que para ele arte e realidade não artística passam a funcionar nas mesmas condições e já não há uma posição vantajosa, ao invés de refletir a vida, a arte contemporânea se soma a seus conteúdos (cf. BAUMAN, 1998, p. 135). E assim, como afirma Cátia Inês Negrão Berlini de Andrade, "os textos de Tabucchi inserem o real na ficção, destacando sempre a preocupação com as questões existenciais (...) na esperança que, de um modo ou de outro, a ficção possa "interferir" na realidade. (ANDRADE, 2012, p. 19). E podese pensar que nada é mais presente na vida humana, passível de interferências e de "somar-se" à arte, do que a temática amorosa. Por isso, analogamente à canção italiana apresentada como epígrafe da obra, o emissor da carta, "bom como era", em dado momento afirma: "a vida é assim mesmo, é feita de idas e vindas" (TABUCCHI, 2004, p. 113), ao que se poderia 
acrescentar: o amor também. Talvez esse seja o grande mérito da obra de Tabucchi: "somarse" à vida, traduzindo a instabilidade da existência, dos sujeitos e dos sentimentos que, mais do que nunca, permanecem em eterno e instável movimento em nossa era pós-moderna.

\section{Referências}

ANDRADE, C. I. N. B. Um passeio pelos bosques ficcionais de Antonio Tabucchi. Revista Rascunhos Culturais, v. 3, n. 6, p. 13-28, 2012.

BAUMAN, Z. O mal-estar na pós-modernidade. Tradução de Mauro Gama e Cláudia Martinelli Gama. Rio de Janeiro: Zahar, 1998.

BAUMAN, Z. Amor líquido: sobre a fragilidade dos laços humanos. Tradução de Carlos Alberto Medeiros. Rio de Janeiro: Zahar, 2004.

BAUMAN, Z. Identidade: entrevista a Benedetto Vecchi. Tradução de Carlos Alberto Medeiros. Rio de Janeiro: Zahar, 2005.

BRANDÃO, I. L. B. Lembranças de fins de tardes com Tabucchi. O Estado de São Paulo, São Paulo, 28 de março de 2012. Disponível em:

https://cultura.estadao.com.br/noticias/geral,lembrancas-de-fins-de-tardes-com-tabucchi-imp,854320. Acesso em 27 mar. 2020.

EAGLETON, T. As ilusões do pós-modernismo. Tradução de Elisabeth Barbosa. Rio de Janeiro: Zahar, 1998.

HARVEY, D. Condição pós-moderna. São Paulo: Loyola, 1992.

HUTCHEON, L. Poética do Pós-Modernismo: História, Teoria, Ficção. Tradução de Ricardo Cmz. Rio de Janeiro: Imago, 1991.

JAMESON, F. Pós-Modernidade e sociedade de consumo. Novos Estudos, n. 12, p. 16-26, 1985.

PERRONE-MOISÉS, L. Altas literaturas. São Paulo: Companhia das Letras, 1998.

TABUCCHI, A. Il gioco del rovescio. Milão: Feltrinelli, 1998.

TABUCCHI, A. Está ficando tarde demais: romance em forma de cartas. Tradução de Ana Lúcia Belardinelli. Rio de Janeiro: Rocco, 2004.

VATTIMO, G. O fim da modernidade: niilismo e hermenêutica na cultura pós-moderna. Tradução de Eduardo Brandão. São Paulo: Martins Fontes, 2002.

Recebido em: 03 de julho de 2020 Aceito em: 13 de outubro de 2020 Publicado em dezembro de 2020 